\title{
INTERPROFESSIONAL SHARED DECISION-MAKING: A LITERATURE REVIEW
}

\author{
Chaina Hanum ${ }^{1}$, Ardi Findyartini ${ }^{2 *}$ \\ ${ }^{1}$ Master Program in Medical Education, Universitas Indonesia, Jakarta - INDONESIA \\ ${ }^{2}$ Department of Medical Education, Faculty of Medicine, Universitas Indonesia, Jakarta - INDONESIA
}

Submitted: 02 Sep 2019; Final Revision from Author: 05 Mar 2020; Accepted: 12 Mar 2020

\begin{abstract}
Background: The increasing complexity of health problems consequently demands problem solving from various perspectives of health professionals. The interprofessional approach in solving health problems, by working together with patients, their families, and the communities is called Interprofessional Shared Decision-Making (IP-SDM). The capability of various health professionals in IP-SDM becomes one of the abilities to be achieved in Interprofessional Collaborative Practice (IPCP). IP-SDM learning should also be achieved through Interprofessional Education (IPE).

Method: This is a literature study aiming to elaborate IP-SDM and its correlation to IPCP and IPE. Results: IP-SDM is a decision making process which involves collaboration between two or more health professionals and also patients aiming at idenfication of best choices while considering patients' preferences. IP-SDM consists of two core processes: shared decision-making (SDM) between health professionals and patients and collaborative clinical reasoning (CCR) among health professionals.

Conclusion: Although SDM and CCR learning has been widely reported, including the potential emphasis in interprofessional education and interprofessional collaborative practice, IP-SDM learning is still limited. For this particular reason, further exploration is needed regarding the development of IP-SDM learning method in IPE, especially in Indonesia context.
\end{abstract}

Keywords: interprofessional shared decision-making, shared decision-making, collaborative clinical reasoning, interprofessional collaborative practice, interprofessional education

\section{PRACTICE POINTS}

- Interprofessional Shared Decision-Making (IP-SDM) is a collaboration of various health professionals and patients in the decision-making process.

- IP-SDM is a combination of shared decision-making (the process of making decision between health professionals and patients) and collaborative clinical reasoning (the process of clinical reasoning involving several health professionals).

*corresponding author, contact: ardi.findyartini@ui.ac.id 


\section{INTRODUCTION}

Nowadays health problems are becoming more complexed with the increase of chronic disease and comorbidity. ${ }^{1}$ Therefore, health professionals are required to be able to work together and collaborate to solve patients' problems, including in the decision making process. ${ }^{2}$ Collaboration of two or more health professionals together with patients in the decision making process is called Interprofessional Shared Decision-Making (IP-SDM). ${ }^{3,4}$ This concept shows that health professionals from different backgrounds not only need to work together in the decision making process, but the involvement of patients is also necessary. Collaborative clinical decision making becomes an inseparable part of the interprofessional collaborative practice, hence the learning process on this concept should also be achieved through IPE.

Interprofessional Collaborative Practice (IPCP) is a practice of collaboration between two or more professions. ${ }^{5}$ According to $\mathrm{WHO},{ }^{6}$ interprofessional collaborative practice is a practice carried out by several health professionals from different backgrounds by involving patients, patients' families, carers, and communities to achieve a high quality health service. Collaborative practice could be related to clinical and non-clinical issues, such as diagnosis making, therapeutic management, health communication, health policy, and sanitation.

The main purpose of an interprofessional collaboration is to improve health services based on patients' needs and concerns (patient-centered care). ${ }^{7}$ Making a clinical decision not only has to involve the patients, but also has to prioritize the patients' concerns. Other advantages of interprofessional collaboration are the increase patients' outcomes with chronic illness, patient safety, access and coordination of the health care system; and the decrease of complications and mortality rates, the number of clinical errors, and consequently duration and cost of treatment. ${ }^{6,8}$ The benefits of this collaboration could also be felt by the health professionals involved, such as increased job satisfaction and reduced duration of work. ${ }^{9}$

In the interprofessional collaboration, an effective team is needed with every member having qualified interprofessional competence. Interprofessional Education Collaborative (IPEC) $)^{7,10}$ suggested four competency domains:

Values and ethics for interprofessional practice; including the ability to work with other professions by maintaining virtues and mutual respect as the main foundation in building an effective interprofessional collaboration.

Roles and responsibilities; including the ability to use the knowledge of one's own role and those of other health professions to solve patients' problems.

Interprofession communication; including the ability to communicate with patients and their families, the communities, and other health professionals in a responsive and responsible manner.

Teams and teamwork; including the ability to play their role in a team effectively, as a leader and team member, by applying the values and principles of team dynamics.

The implementation of interprofessional collaborative practice can vary widely depending on local needs and health policies, ${ }^{5}$ also the level of healthcare facilities. Setiadi et al. ${ }^{11}$ stated that there are three factors influencing interprofessional collaboration in Primary Health Care (Puskesmas) in Indonesia; personal factors such as interaction between health professionals and hierarchical cultures, organizational factors such as support from health institutions and integrated information systems in healthcare facilities, and system factors such as government policy. Yusra et al. ${ }^{2}$ identified several factors which probably could interfere with the collaboration process. Beside the existence of a hierarchical culture, factors of age and duration of work experience could also affect the process of collaboration. ${ }^{12}$

Interprofessional collaboration concept is learned through an interprofessional education (IPE). CAIPE ${ }^{5}$ defined IPE as a learning process carried out with, from, and about two or more health professions to improve the process of collaboration and the quality of health care. The prepositions "with", "from", and "about" indicate that the learning process in IPE is conducted interactively and equitably..$^{13}$ IPE is a learning process that supports the collaboration 
process, through understanding the relationships among health professionals, exploring the process of combining various expertise in improving the quality of health care and patient safety. ${ }^{5}$ The goal of IPE is to increase knowledge, skills, attitudes, and behaviors towards collaborative practice, in order to improve the quality of clinical practice. ${ }^{14}$

Significant effort is needed to prepare and implement IPE, both in terms of resources (e.g. the involvement of various health professions, resepectable finance), and the development of the IPE context and curriculum. However, a well-designed and implemented IPE can have positive results in the learning process of interprofessional collaboration. ${ }^{15}$ One of the main requirements in preparing IPE is an interprofessional champion, which is a health professional who has the commitment and experience in interprofessional collaboration, has the capability to be a role model, to provide motivation and real examples in interprofessional collaboration, and to change the negative stereotypes of interprofession. ${ }^{13}$ IPE is developed by considering the stages of the students, the undergraduate stage (pre-licensure IPE) or the postgraduate stage (post-licensure IPE). ${ }^{13-15}$

Patients always become a center in interprofessional collaborative practice and should be a critical context used in interprofessional education. Currentliterature on IPE has been focusing on theories underpinning IPE,$^{16}$ approaches of IPE implementation, ${ }^{13-15}$ and the outcomes. ${ }^{14}$ Whereas for IPCP, the implementation in various settings, the influencing factors and the outcomes have been reported. 2, 6, 8,9,12,17 How patients (and their families) can be involved in clinical decision-making as reflected in IP-SDM, however, is less explored. In this article, the author conducted a literature study on IP-SDM and its correlation to the interprofessional collaborative practice and interprofessional education. This article could be used as a tool to reflect on the current IPE, especially regarding the sufficiency of IPE as a platform in developing IP-SDM capabilities.

\section{METHODS}

This is a literature study on IP-SDM and its correlation to interprofessional collaborative practice and interprofessional education. Literature exploration is done by accessing the SpringerLink, ScienceDirect, Taylor \& Francis, and Google Scholar databases. Literature search was conducted from March 20 to May 5, 2019, using the key words of of "interprofessional shared decision-making", "shared decision-making", "collaborative clinical reasoning", as well as the combination of these three keywords with "interprofessional collaboration practice" and "interprofessional education". Based on the literature search, 25 literatures related to IP-SDM, shared decision-making, collaborative clinical reasoning, and its correlation to IPCP and IPE were obtained. The systematic steps in identifying relevant articles is described in Figure 1. Both authors screened and selected them and further read the full text of eligible articles. 


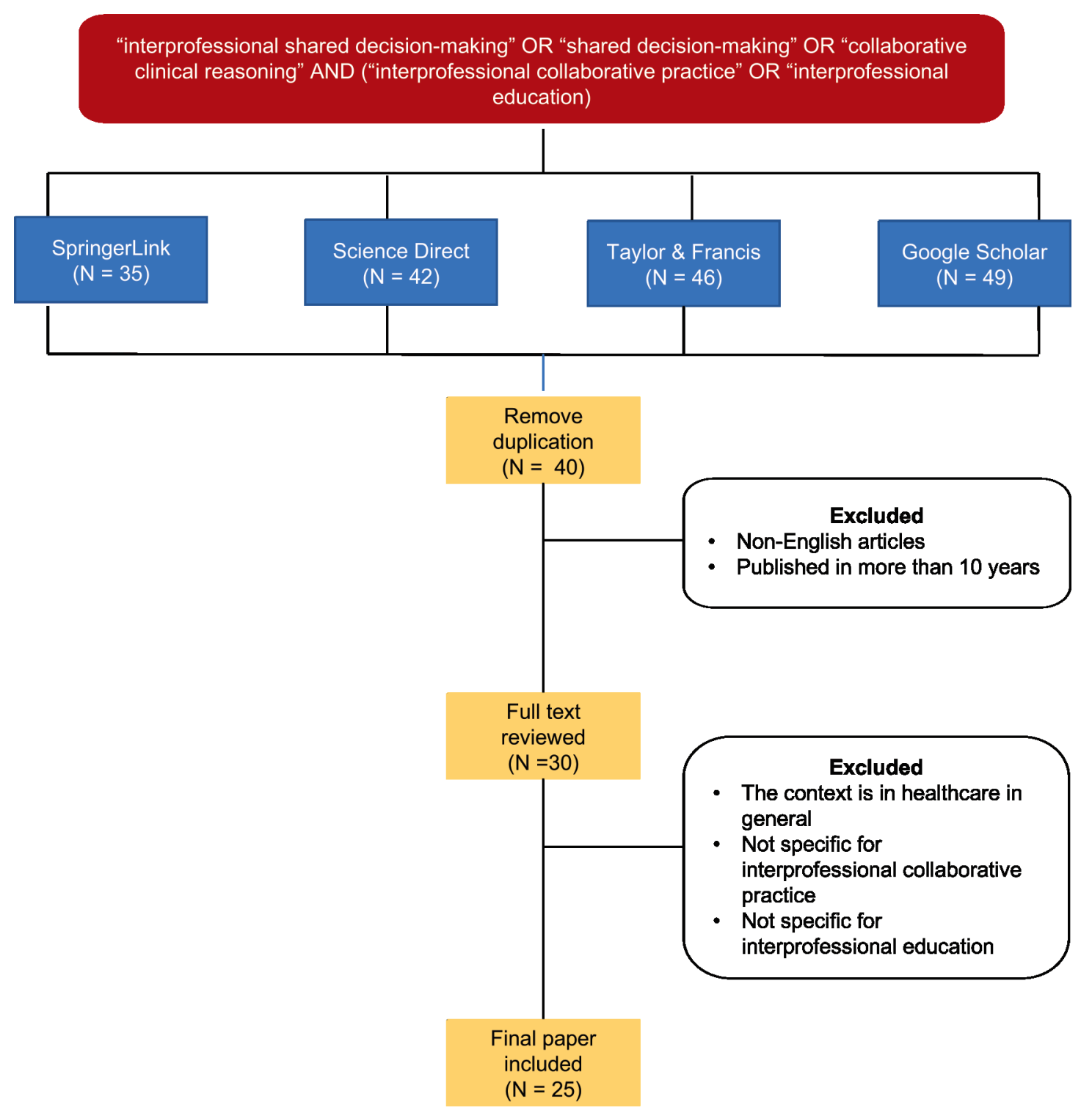

Figure 1. Systematic flow of literature searching

\section{RESULTS AND DISCUSSION}

\section{Shared decision-making}

Collaborative clinical decision making is often referred to shared decision-making (SDM). According to Légaré \& Witteman, ${ }^{18}$ SDM is an interpersonal and interdependent collaboration process in which health care providers and patients influence each other, in the decision-making process regardingthe patient's problems. Meanwhile, Barr et al. ${ }^{19}$ stated SDM is a process carried out by health professionals and patients in making decisions through the use of the best scientific evidence and patients' considerations and choices.

SDM emphasizes the importance of patients' involvement in the decision-making process. Decisions are made not only based on the patients' clinical problems, but also considering the patients' wishes and preferences, as well as the patients' capacity to comply with the decisions. ${ }^{19}$ SDM is also patient specific, which means the approach taken in SDM varies depending on the patients' clinical problems, the level of expertise of the health professionals involved, and the personal attributes 
of the patients and their family including language and cultural factors. SDM is generally applied to problems with uncertainty, such as problems that have several choices of solutions. ${ }^{18}$

To ensure SDM is successful, both the health professional team and the patient must understand that decision making should use the best clinical evidence. ${ }^{4,18}$ Moreover, both parties should be mutually informed and consider all the pros and cons of each option. Decision making must be mutually agreed by the team of health professionals and patients, with considering preferences and values of the patients. ${ }^{4}$

\section{Collaborative Clinical Reasoning}

Clinical reasoning is one of the important capabilities to be possessed by various health professionals. This ability is very necessary in making the best and wisest decision for the patient. According to Higgs et al., ${ }^{20}$ clinical reasoning is the process of thinking and making decisions in professional practice through analysis of various factors in a particular clinical problem. Trowbridge et al. ${ }^{21}$ stated that clinical reasoning is a cognitive and non-cognitive process carried out by the health professionals consciously and unconsciously, through interactions with patient and the environment to explore and interpret data, consider the benefits and risks of a procedure, and consider the patients' preferences in determining diagnosis and therapy to improve patients' wellbeing.

Clinical reasoning is a thinking process involving patients, health professionals, and clinical problems. The health professional plays the biggest role in the decision-making process. In health care practice, the health professionals must fulfill the competency standards and be responsible on all procedures and decisions made. ${ }^{20}$ Therefore, in every decisionmaking process, the health professionals must consider various aspects including ethics, morals, and patients' concerns, and should have capability ${ }^{22}$ and expertise ${ }^{23}$ in clinical reasoning.

With the development of interprofessional collaborative practice, solving patients' problem is carried out through collaboration of two or more health professions. The clinical reasoning process that involves several health professions is called collaborative reasoning or collaborative clinical reasoning (CCR). According to Blondon et al. ${ }^{24}$ CCR is a process within a team to form a thinking framework (mental model) that is everyone agreed upon regarding patients' problem and its management. Meanwhile Kiessewetter, Fischer, and Fischer ${ }^{25}$ stated that CCR is a negotiation process by health professional team regarding patients' diagnostic, therapeutic, and prognostic, to construct a management plan, and reduce uncertainty.

Clinical reasoning collaboration can be applied in the process of diagnostic reasoning, preparing and implementing patient management, monitoring the patient's condition, interprofessional communication, and providing explanations to patients. ${ }^{24}$ The stages of the clinical reasoning collaboration process can be carried out using a modified Schoenfeld approach. ${ }^{25}$ The five stages are as follows:

- The first stage of clinical reasoning is exploring data by each health professional based on their expertise background. ${ }^{26}$ Insufficient data due to unexplored information can lead to an inaccurate hypothesis.

- Stage of hypotheses formation and analysis by each health professional, which depends on the level of their individual expertise. A similar level of experience possessed by team members can increase the accuracy of the diagnosis. ${ }^{25}$

- Stage of information exchange among health professionals, in order to obtain comprehensive data. ${ }^{25}$ This is influenced by communication and interaction patterns among health professionals. $^{26}$

- Stage of information representation, by distributing informations to all team members to ensure data synchronization and anticipation of missing data. ${ }^{24}$ The process of information distribution can be done parallel at the same time, such as face-to-face and by phone communication, or asynchronously as through patients' medical records and text messages. ${ }^{26}$

- Stage of evaluation and integration phase, which is a process of negotiating scientific evidence by all collaborative team member. The scientific 
evidence could be an internal evidence, which is the evidence that is processed by the collaborative team based on patients' data, as well as external evidence based on literature studies. This stage is strongly influenced by the level of difficulty of the case and the expertise of each health professional involved..$^{25}$

One example of collaborative clinical reasoning is the collaboration of doctors and nurses in the simulation of the handling emergency cases in internal medicine ward, through research conducted by Blondon et al. ${ }^{25}$ In the initial stage of clinical reasoning, doctors and nurses will collect informations from patients, analyze, and arrange hypotheses according to their expertise background. Information then is exchanged between doctors and nurses, and the determination of the patient's diagnosis is based on the analysis of the information regarding clinical evidence from both parties. Another example of collaboration in managing patient problems is the formation of management plan undertaken by doctors, and nurses will carry out this management plan. However, nurses can communicate their recommendations regarding the patients' management to doctors. ${ }^{24}$

\section{Interprofessional Shared Decision-Making (IP-SDM)}

A study by Stacey et al. ${ }^{27}$ concluded that various existing SDM models could not be able to facilitate interprofessional approach. Therefore, Légaré et al. $^{3}$ developed a concept that facilitates an interprofessional approach in the SDM process, namely interprofessional shared decision-making (IP-SDM). IP-SDM is defined as a decision making process involving collaboration between two or more health professionals and also patients, by identifying the best choices, while considering patients' preference. ${ }^{3,28}$ The correlation of SDM and clinical reasoning collaboration to IP-SDM is illustrated in Figure 2.

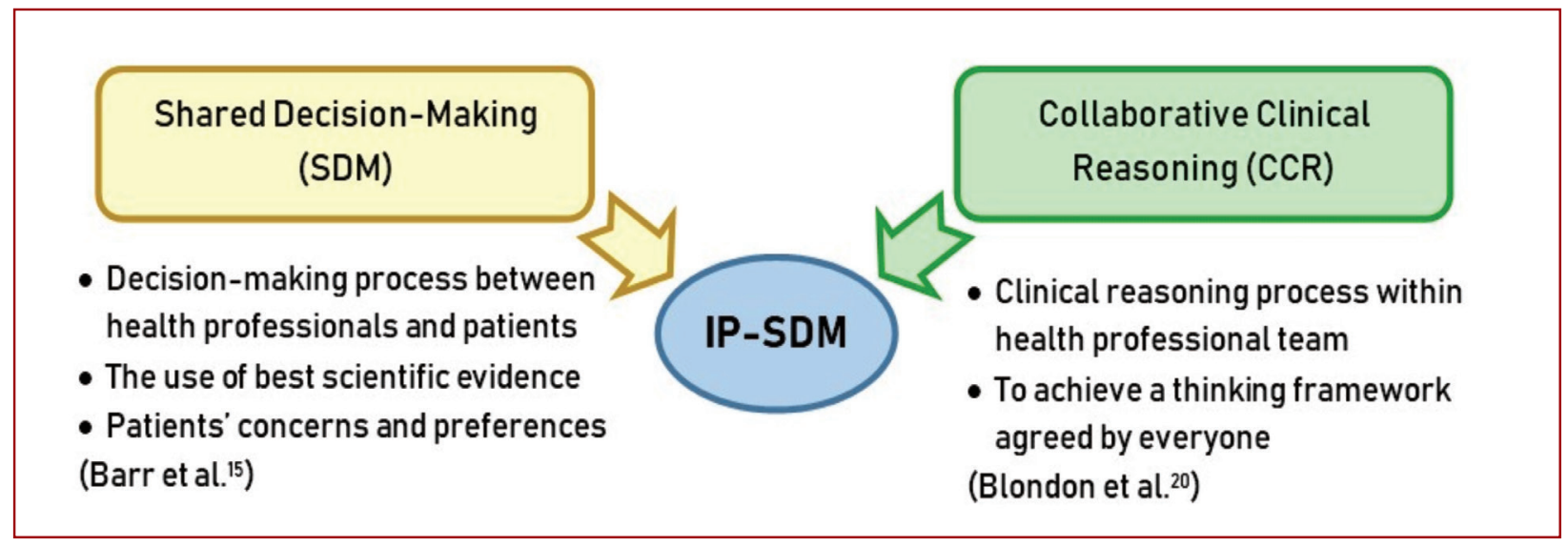

Figure 2. Correlation of SDM, CCR, and IP-SDM Scheme

According to Körner, Ehrhardt, and Steger, ${ }^{29}$ IP-SDM requires two forms of participation, external and internal participation. External participation could be in the form of communication, coordination, and collaboration between patients and the health professionals in the decision-making process. Meanwhile internal participation is a form of collaboration among several health professionals to formulate patients' management plan. In IP-SDM there are three stages of interaction; the micro interaction which is carried out between patients and the health professionals individually, the meso interaction in the health professional team, and the macro interaction in the organization or health service level.

The IP-SDM model is shown in Figure 2..$^{30,31}$ The environment describes the context that supports the overall IP-SDM process. This component includes social norms, habits and policies in health care 
institutes, and the health care system in general. Social norms include cultural values, habits and policies in the community, the health professional team, and the patient and family, which all influence the decision-making process. The health care system is influenced by government policies, accreditation standards, and health care practice guidelines developed by professional organizations. ${ }^{31}$

IP-SDM emphasizes the importance of the active role of patients and their family in making decisions. A health professional team with great collaboration is also needed to support the sustainability of the IPSDM. In the health professional team, an initiator is needed to be responsible ${ }^{32}$ and to facilitate the decision-making process. The role of the initiator can be carried out by all health professions, either doctors, nurses, pharmacists, or other health professions. ${ }^{31}$

In IP-SDM there are six stages in making a decision, ${ }^{3,4}$ which can be done iteratively as needed. This describes the possibility of reviewing a predetermined decision, if the expected outcome is not yet reached. ${ }^{31}$ One example of IP-SDM implementation is in decision making process in the neonatal intensive care unit (NICU) by the interprofessional collaborative team and the patient's family. ${ }^{32}$ The IP-SDM process in NICU involves four important roles in the decision making process, the initiator or leader who facilitates the process of making a decision, professional experts who provide information and insights in handling the case, team members who synthesize and integrate overall information, and parents as patient guardians in decision making. This study also identified several important aspects that occurred during the IP-SDM process, such as aspect of collaboration, information exchange, consideration of the benefits and risks of various available solutions, scientific evidence, the credibility of an opinion, and consensus achieved. Consensus is not only seen as the overall agreement of team members (full agreement), but also acceptance of other team members' opinion. ${ }^{32}$

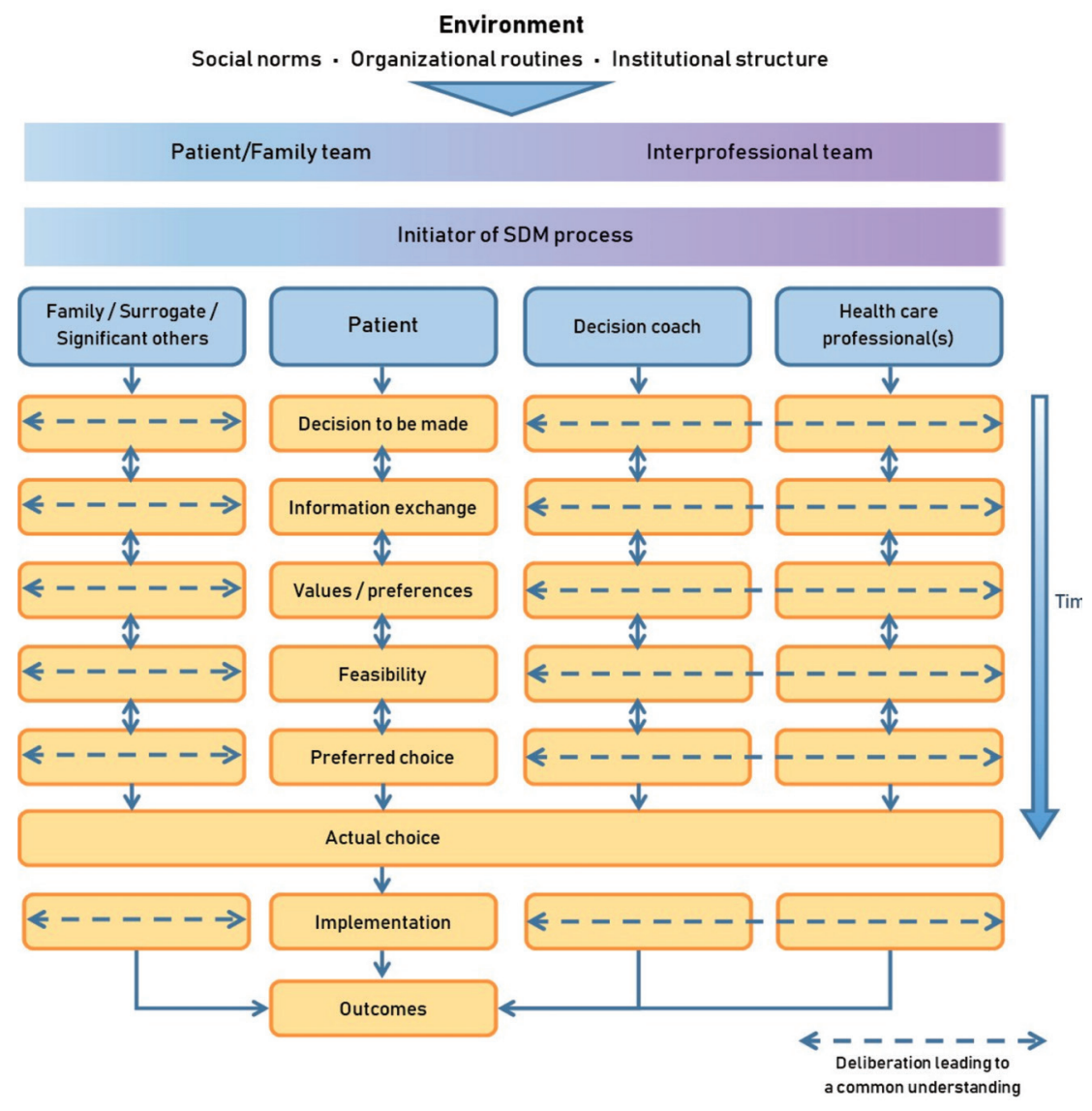

Figure 3. IP-SDM Modelele,29 
In managing a 50 years-old male patient with diabetes mellitus whose blood glucose is not yet controlled despite ongoing treatment for the past 5 years in a district hospital, the 6 stages of IP-SDM can be described as follows: $:^{3,4}$

1. Stage 1 - At this stage the health professional team in the diabetes mellitus outpatient clinic should be aware that decisions should involve multiple parties:

- a general internist who facilitates shared decision making, gathers all information and takes responsibility in decision making;

- general practitioners, sport medicine specialists, nurses, nutritionists, and pharmacists who understand the best solutions for patients;

- the patient and the family member who can be the key caregiver at home.

2. Stage 2 - All health professionals exchange key information among themselves and the team leader discuss with the patient and his caregiver about the benefits and risks of each solution.

- follow up results on possible occurrence of diabetes mellitus complications;

- evaluation on the patient's diet habit, physical exercise and his compliance on the drug treatment;

- possible side effects of the oral hypoglycemic drugs.

3. Stage 3 -Clarifying values by health professionals who work on the particular case. This stage can be done in integrated manner with stage 2 and aims to explore the reasoning of each party.

4. Stage 4 - Exploring feasibility aspects of each solution. Following stage 2 and 3, the team leader should synthesise best solutions and discuss them with the team members as well as with the patients and his caregiver.

5. Stage 5 - Making a decision agreed by all parties. Upon comprehensive evaluation, the team leader makes decisions agreed by the team members and discuss the agreed solutions with the patient and his caregiver.

6. Stage 6 - Providing support to patient to obey all decisions made. At this stage, the team leader should be able to explore whether the patient and his caregiver understand the agreed solutions on diabetes mellitus management. The team leader should also identify whether the patient would need more detailed information on how to manage his disease better and refer it to the respected team member if necessary (e.g refer the patient to obtain detailed information on managing his diet to the nutritionist).

\section{Challenges on SDM and IP-SDM}

SDM and IP-SDM have not been fully applied in health practice. This is influenced by several challenges related to SDM implementation. In terms of time, SDM needs more time to facilitate the involvement of each health professional to collect and process data and make decisions. Moreover, some patients are not interested in being involved in the SDM process, such as geriatric patients, immigrants, and patients with low education levels. Cases that are too complex are also often considered as a challenge in SDM. ${ }^{18}$

Légaré et al. ${ }^{31}$ identified various potential challenges in IP-SDM, such as time limitation and the existence of a hierarchical culture. Even though interprofessional collaborative practices emphasize equality among health professionals, there is still perception that doctors' authority and privileges are higher than other health professions. Nowadays there are still many health professionals who do not know how to implement SDM, hence they will find it more inconvenient when using the interprofessional collaborative approach in SDM. ${ }^{30}$

To overcome these challenges, some efforts are needed to improve the implementation of SDM and IP-SDM. In general, improvement efforts are carried out through two approaches, developing decision aids for patients and training for health professionals through interprofessional education. ${ }^{18}$ Decision aids is a tool for patients with evidence-based information to increase knowledge and understand of the conditions faced, in order to increase patients' participation in making decisions for themselves. ${ }^{33}$ 


\section{Learning SDM dan IP-SDM}

Kiesewetter et al. $^{34}$ proposed a CCR learning framework in IPE; the thinking process of a health professional in the interprofessional collaborative team is influenced by two things, the illness script and the internal collaboration script. Illness script is a structure of knowledge about the categorization of diseases along with the characteristics and the pathological pahtways. While the internal collaboration script is a compilation of one's knowledge on how to interact with others in a situation, and is obtained through repeated exposure to the interprofessional collaboration learning process. Internal collaboration scripts consist of four components that are arranged in stages, play, scene, scriptlet, and role. The internal collaboration scripts scheme is shown in Figure 4.

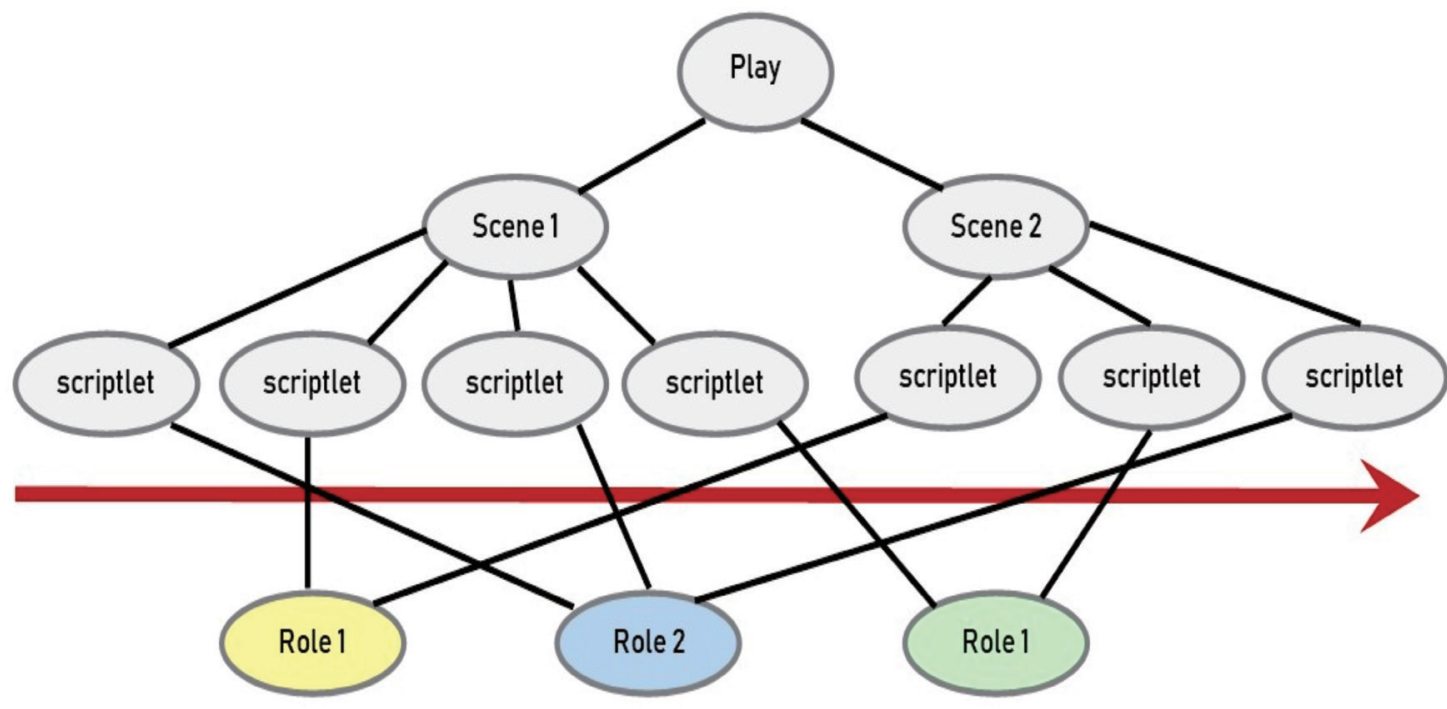

Figure 4. Internal collaboration scripts structure ${ }^{32}$

Using the analogy of a performance staging, the internal collaboration script in Figure 4 can be explained as follows ${ }^{34}$ :

- Play is describing the clinical situation in which the collaboration process takes place, for example in an emergency situation in the emergency room or non-emergency situation in the outpatient clinic. Play consists of several scenes.

- Scene is illustrating some of the stages to be carried out in a clinical situation. For example, scenario 1 is the stage of introducing and exploring the patient's identity, followed by scenario 2 which is exploring informations regarding the patient's health problems, followed by scenario 3 which is examining patient's vital sign and physical examination, followed by scenario 4 in terms of diagnostic examination, and so forth. Scenarios are composed by several scriptlets.
- Scriptlet or script is describing each individual's knowledge about the activities in a particular clinical scenario. For example, in scenario 2 (exploring information on a patient's health problems) there is a scriptlet of digging up the patient's history of current illness or a scriptlet of asking for the patient's medication history.

- Role is a component that describes the role that will be played by each team member in a situation (play). Not all roles will be involved in a scriptlet.

The following is the example of handling a diabetic ulcer case in an inpatient situation as a play by several health professionals such as doctor, nurse, and nutritionist.

- Some stages of the scene in handling this case is exploring the patient's medical history along with habits and eating patterns, doing physical 
examination and laboratory examination, providing therapy and management, and providing education.

- In the scene of providing therapy and management, there are several scriptlets, i.e., providing therapy related to diabetes mellitus management, treating the ulcers, and arranging the suitable diet for the patient.

- Some actions that will be performed by the doctor are exploring the patient's medical history based on the doctor's expertise, doing physical examination, analyzing physical examination results, and establishing the diabetes mellitus therapy. Actions that will be played by nurse are exploring the patient's medical history based on the nurse's expertise, doing vital signs examination, and treating the ulcers. While the actions that will be done by nutritionist is exploring the patient's medical history, especially informations relating to their diet, examining the patient's nutritional status, and arranging a specific diet based on the patient's nutritional needs and clinical conditions.

The learning method used in IPE which resembles clinical situations should be able to develop an internal collaboration script component in each health professional as described above, for them to be able to recognize their own role and other health professions' roles in every health care situation. ${ }^{34}$

Some methods have been implemented on the SDM learning. ${ }^{35}$ In undergraduate education (prelicensure), the topic is generally delivered through case-based learning (CBL) and problem-based learning (PBL),${ }^{15}$ by analyzing a case in groups, using various perspectives of the health profession. Analyzing the case could be done by using Interprofessional Team Reasoning Framework (IPTRF), as a thinking framework in solving patients' problem together. ${ }^{36}$ IPTRF was developed by Creighton University as a tool in learning cases in IPE. The use of IPTRF can also enhance the process of interprofessional collaboration in terms of teamwork aspect, leadership, communication, values, and ethics.

SDM learning can also be done in the form of role play, both using simulated patient and virtual technology. ${ }^{15,37}$ Several studies have shown that the use of real cases in CBL improved the clinical reasoning process in team and increased students' understanding of SDM. ${ }^{15,38}$ In general, learning SDM has a positive impact in improving skills, attitudes, and self-confidence toward SDM. ${ }^{37}$

Another method in learning SDM and interprofessional collaboration at the pre-licensure stage is through a student-run free clinic (SRFC). ${ }^{39}$ SRFC is a health clinic for the people with low socioeconomic status in the United States, with students as a health service provider under an expert's supervision. Student involvement in SRFC is voluntary, and consists of various health profession backgrounds such as medicine, dentistry, occupational therapy, ostheopathic, pharmacy and several other health professions. ${ }^{40}$ In SRFC, the students work in an interprofessional team to gather informations and conduct examinations on patients, discuss patients' problems, and provide health care to patients. Student involvement in SRFC can improve students' attitudes and perceptions towards interprofessional collaboration and improve their clinical reasoning abilities. ${ }^{39,41}$

In the post-graduate stage (post-licensure) SDM training is delivered in various methods and ways of delivery. Harman et al. ${ }^{42}$ developed a training program to improve the physicians' behavior towards SDM, which was conducted when doing rounds of inpatients. The training program included Patient Engagement Project (PEP) workshop on SDM, followed with a campaign of using SDM in the form of posters, pocket cards, and electronic messages as a reinforcement of previously received SDM material. Assessment of physician's behavior towards SDM was carried out before and after the intervention period using the Rochester Participatory DecisionMaking Scale (RPAD). Through this program, there was a significant increase in behavior towards SDM.

Légaré et al. ${ }^{35}$ developed a mapping of various international SDM learning processes. The research showed that the learning process of SDM in developed countries was very diverse, whereas in developing countries was still limited. The learning methods used were quite varied; therefore, the evidence of effectiveness of the training program 
also varied. Besides, SDM learning was more widely applied at the post-licensure stage, while the research related to SDM learning at the pre-licensure stage was still limited. This indicates a gap of knowledge about SDM at the pre-licensure and post-licensure stages.

Gummesson, Sundén, and $\mathrm{Fex}^{43}$ designed a CCR learning method by using clinical case which was delivered narratively. The case was used as a trigger for discussion in the interprofessional group of nursing and physiotherapy students. Another method of CCR learning was carried out by Schlipalius and Delany, ${ }^{44}$ by conducting interactive training for medical and midwifery students. The training was in the form of case study to develop a pregnancy care plan, using four stages of thinking: case identification, case management, evaluation of care categories based on the patient's pregnancy risk, communication, and documentation. Through the case study in the training, participants could improve their thinking skills in preparing pregnancy care plan.

Körner, Ehrhardt, and Steger ${ }^{29}$ designed the IPSDM training in two stages. The first stage was a training related to external participation, in terms of training to improve the attitudes, knowledge and skills of the health professionals towards SDM. This stage was focused on the SDM staging and empathy in the relationship between patients and the health professionals. The second stage of training dealt with internal participation, aimed at increasing the participation of every health professional in the interprofessional team. This stage was focused on the process of communication and teamwork.

Nowadays, research related to IP-SDM learning method is not widely reported. One method that has been used in IP-SDM training is the use of vignette in the form of video. The vignette used real cases as examples, and was organized based on IPSDM concepts and stages. Through the use of video vignettes in training, the knowledge and confidence of participants towards IP-SDM were significantly increased. ${ }^{30}$

The IP-SDM concept has been developed only for the last ten years. Research related to the concept and implementation of IP-SDM is still evolving. Research in developing the IP-SDM learning model is also expected to be increased..$^{45}$ Currently in Indonesia there is no research related to the implementation and development of the IP-SDM learning model, thus the opportunities for conducting research in this field are still quite large.

\section{CONCLUSION}

Currently, IP-SDM as a new paradigm that combines interprofessional collaboration and shared decisionmaking is evolving. Interprofessional collaborative approach and actively patient involvement are very important in making clinical decisions. Through the IP-SDM approach the quality of health services based on patient interests are supposedly to be enhanced.

Interprofessional education is an important approach in preparing health professionals to be ready to collaborate in health care practice. IPE is intended to develop various interprofessional competencies, one of which is IP-SDM. Eventhough the research related to learning IP-SDM in IPE is still limited, this indicates that there are still many areas need to be explored in relation to learning IP-SDM in IPE, including in Indonesia. Hence, further research or study is needed regarding the IP-SDM developmental integration in IPE in Indonesia.

\section{RECOMMENDATION}

The development of IP-SDM learning in Indonesia needs to pay attention to various factors, such as the systems of health service, the forms of existing interprofessional collaborative practice implementation, and socio-cultural factors. The development of the IP-SDM learning model in IPE in Indonesia may refere to the 3P model regulation, which is having a clear IP-SDM learning context, supported by educational institutions and health service institutions, involving interprofessional champions as teaching staffs, and using authentic learning methods that resemble the real practices of interprofessional collaboration in Indonesia.

\section{LIST OF ABBREVIATIONS}

IPCP Interprofessional Collaborative Practice

IPE Interprofessional Education 


$\begin{array}{ll}\text { IP-SDM } & \text { Interprofessional Shared Decision- } \\ & \text { Making } \\ \text { SDM } & \text { Shared Decision-Making } \\ \text { CCR } & \text { Collaborative Clinical Reasoning }\end{array}$

\section{COMPETING INTERESTS}

The authors report no conflicts of interest. The authors are solely responsible for the content and writing of this article.

\section{AUTHORS' CONTRIBUTIONS}

The manuscript writing was led by $\mathrm{CH}$ and developed by $\mathrm{CH}$ and AF. AF led the revision of the manuscript. All authors analysed and appraised the literature cited in the paper and approved the final version of the manuscript.

\section{REFERENCE}

1. World Health Organization. Patient Safety Curriculum Guide: Multi-professional Edition. Geneva: World Health Organization; 2011.

2. Yusra RY, Findyartini A, Soemantri D. Healthcare professionals' perceptions regarding interprofessional collaborative practice in Indonesia. J Interprofessional Educ Pract [Internet]. 2019;15:24-9. Available from: https://doi. org/10.1016/j.xjep.2019.01.005

3. Légaré F, Stacey D, PouliotS, Gauvin F, Desroches $\mathrm{S}$, Kryworuchko J, et al. Interprofessionalism and shared decision-making in primary care: a stepwise approach towards a new model. J Interprof Care. 2011;25:18-25.

4. Costanzo C, Doll J, Jensen GM. Shared Decision Making in Practice. In: Higgs J, Jensen GM, Loftus S, Christensen N, editors. Clinical reasoning in the health professions. 4th ed. Edinburgh: Elsevier; 2019. p. 181-90.

5. Barr H, Low H. Introducing Interprofessional Education. Centre for The Advancement of Interprofessional Education (CAIPE); 2013.

6. World Health Organization. Framework for Action on Interprofessional Education $\mathcal{E}$ Collaborative Practice [Internet]. Geneva; 2010. Available from: http://www.who.int/hrh/nursing_midwifery/ en/\%0ACopies
7. Interprofessional Education Collaborative. Core Competencies for Interprofessional Collaborative Practice. Washington, DC; 2011.

8. Kaiser L, Bartz S, Neugebauer EAM, Pietsch B, Pieper D. Interprofessional collaboration and patient-reported outcomes in inpatient care : protocol for a systematic review. Syst Rev. 2018;7(126):1-6.

9. Bosch B, Mansell H. Interprofessional collaboration in health care: Lessons to be learned from competitive sports. Can Pharm J. 2015;148(4):176-9.

10. Interprofessional Education Collaborative. Core Competencies for Interprofessional Collaborative Practice : 2016 Update. Washington, DC; 2016.

11. Setiadi AP, Wibowo Y, Herawati F, Irawati S, Setiawan E, Presley B, et al. Factors contributing to interprofessional collaboration in Indonesian health centres: A focus group study. J Interprofessional Educ Pract [Internet]. 2017;8:6974. Available from: http://dx.doi.org/10.1016/j. xjep.2017.06.002

12. Soemantri D, Kambey DR, Yusra RY, Timor AB, Khairani CD, Setyorini D, et al. The supporting and inhibiting factors of interprofessional collaborative practice in a newly established teaching hospital. J Interprofessional Educ Pract [Internet]. 2019;15:149-56. Available from: https://doi.org/10.1016/j.xjep.2019.03.008

13. Thistlethwaite JE, Vlasses P. Interprofessional Education. In: Dent JA, Harden RM, Hunt D, editors. A practical guide for medical teachers. 5 th ed. Edinburgh: Elsevier; 2017. p. 128-33.

14. Reeves S, Fletcher S, Barr H, Birch I, Boet S, Davies N, et al. A BEME systematic review of the effects of interprofessional education : BEME Guide No . 39. Med Teach. 2016;38(7):656-68.

15. Freeth D, Savin-Baden M, Thistlethwaite J. Interprofessional Education. In: Swanwick $\mathrm{T}$, Forrest K, O'Brien BC, editors. Understanding Medical Education: Evidence, Theory, and Practice. 3rd ed. Hoboken, NJ: Wiley Blackwell; 2019. p. 191-206. 
16. Hean S, Green C, Anderson E, Morris D, John C, Pitt R \& O'Halloran C. The Contribution of Theory to the Design, Delivery, and Evaluation of Interprofessional Curricula: BEME Guide No. 49. Med Teach. 2018. DOI https://doi.org/ 10.1080/0142159X.2018.1432851

17. Zwarenstein M, Goldman J, Reeves S. Interprofessional Collaboration: Effects of Practice-based Interventions on Professional Practice and Healthcare Outcomes. Cochrane Database of Systematic Reviews. 2009; 3. DOI: 10.1002/14651858.CD000072.pub2.

18. Légaré F, Witteman HO. Shared Decision Making: Examining Key Elements and Barriers To Adoption Into Routine Clinical Practice. Health Aff. 2013;32(2):276-84.

19. Barr PJ, Thompson R, Walsh T, Grande SW, Ozanne EM, Elwyn G. The Psychometric Properties of CollaboRATE: A Fast and Frugal Patient-Reported Measure of the Shared Decision-Making Process. J Med Internet Res. 2014;16(1):e2.

20. Higgs J, Jones MA. Clinical decision making and multiple problem spaces. In: Higgs J, Jones MA, Loftus S, Christensen N, editors. Clinical reasoning in the health professions. 3rd ed. Butterworth Heinemann: Elsevier; 2008. p. 3-17.

21. Trowbridge RL, Rencic JJ, Durning SJ. Introduction/Preface. In: Trowbridge RL, Rencic JJ, Durning SJ, editors. Teaching Clinical Reasoning. Philadelphia PA: American College of Physicians; 2015. p. xvii-xxii.

22. Christensen N, Jensen GM. Developing Clinical Reasoning Capability. In: Higgs J, Jensen GM, Loftus S, Christensen N, editors. Clinical reasoning in the health professions. 4th ed. Edinburgh: Elsevier; 2019. p. 427-33.

23. Jensen G, Resnik L, Haddad A. Expertise and clinical reasoning. In: Higgs J, Jones MA, Loftus $\mathrm{S}$, Christensen $\mathrm{N}$, editors. Clinical reasoning in the health professions. 3rd ed. Butterworth Heinemann: Elsevier; 2008. p. 123-35.
24. Blondon KS, Maître F, Bochatay N, Cullati S, Hudelson $\mathrm{P}, \mathrm{Vu} \mathrm{N} \mathrm{V}$, et al. Interprofessional collaborative reasoning by residents and nurses in internal medicine: Evidence from a simulation study. Med Teach. 2017; 39(4):360367.

25. Kiesewetter J, Fischer F, Fischer MR. Collaborative Clinical Reasoning - A Systematic Review of Empirical Studies. J Contin Educ Health Prof. 2017;37(2):123-8.

26. Patel VL, Cytryn KN, Shortliffe EH, Safran C. The Collaborative Health Care Team : The Role of Individual and Group Expertise. Teach Learn Med An Int J. 2000;12(3):117-32.

27. 27. Stacey D, Légaré F, Pouliot S, Kryworuchko J, Dunn S. Shared decision making models to inform an interprofessional perspective on decision making : A theory analysis. Patient Educ Couns. 2010;80:164-72.

28. Légaré F, Stacey D, Brière N, Fraser K, Desroches S, Dumont S, et al. Healthcare providers' intentions to engage in an interprofessional approach to shared decision-making in home care programs: A mixed methods study. J Interprof Care. 2013;182027(3):214-22.

29. Körner M, Ehrhardt H, Steger A. Designing an interprofessional training program for shared decision making. J Interprof Care. 2013;27:14654.

30. Stacey D, Brière N, Robitaille $H$, Fraser $K$, Desroches S, Légaré F. A systematic process for creating and appraising clinical vignettes to illustrate interprofessional shared decision making. J Interprof Care. 2014;28(5):453-9.

31. Légaré F, Stacey D, Gagnon S, Dunn S, Pluye P, Frosch D, et al. Validating a conceptual model for an inter-professional approach to shared decision making: a mixed methods study. J Eval Clin Pract. 2011;17:554-64.

32. Dunn SI, Cragg B, Graham ID, Medves J, Dunn SI, Cragg B, et al. Roles, processes, and outcomes of interprofessional shared decisionmaking in a neonatal intensive care unit: A qualitative study. J Interprof Care [Internet]. 
2018;00(00):1-11. Available from: https://doi. org/10.1080/13561820.2018.1428186

33. Trevena L, McCaffery K. Using Decision Aids To Involve Clients in Clinical Decision Making. In: Higgs J, Jensen GM, Loftus S, Christensen N, editors. Clinical reasoning in the health professions. 4th ed. Edinburgh: Elsevier; 2019. p. 191-200.

34. Kiesewetter J, Kollar I, Fernandez N, Lubarsky S, Kiessling C, Fischer MR, et al. Crossing boundaries in interprofessional education: A call for instructional integration of two script concepts. J Interprof Care. 2016;1-4.

35. Légaré F, Politi MC, Drolet R, Desroches S, Stacey D, Bekker H. Training health professionals in shared decision-making: An international environmental scan. Patient Educ Couns. 2012;88:159-69.

36. Packard K, Chehal H, Maio A, Doll J, Furze $\mathrm{J}$, Huggett $\mathrm{K}$, et al. Interprofessional Team Reasoning Framework as a Tool for Case Study Analysis with Health Professions Students : A Randomized Study. J Res Interprof Pract Educ. 2012;2(3):250-63.

37. Durand M-A, DiMilia PR, Song J, Yen RW, Barr PJ. Shared decision making embedded in the undergraduate medical curriculum : A scoping review. PLoS One. 2018;13(11):1-13.

38. Hendricks-Ferguson VL, Ruebling I, Sargeant DM, Kienstra K, Eliot KA, Howell TG, et al. Undergraduate students' perspectives of healthcare professionals' use of shared decisionmaking skills. J Interprof Care [Internet]. 2018;19. Available from: https://doi.org/10.1080/135 61820.2018 .1443912
39. Seif G, Coker-Bolt P, Kraft S, Gonsalves W, Simpson K, Johnson E. The development of clinical reasoning and interprofessional behaviors : service-learning at a student-run free clinic. J Interprof Care. 2014;28(6):559-64.

40. Student-Run Free Clinic [Internet]. Available from: http://www.studentrunfreeclinics.org/

41. Johnson E, Seif G, Coker-bolt P, Kraft S. Measuring Clinical Reasoning and Interprofessional Attitudes. J Student-Run Clin. 2017;3(1):1-6.

42. Harman SM, Blankenburg R, Satterfield JM, Monash B, Rennke S, Yuan P, et al. Promoting Shared Decision-Making Behaviors During Inpatient Rounds: A Multimodal Educational Intervention. Acad Med. 2019;94(7):1010-8.

43. Gummesson C, Sundén A, Fex A. Clinical reasoning as a conceptual framework for interprofessional learning: a literature review and a case study. Phys Ther Rev [Internet]. 2018;23(1):29-34. Available from: https://doi. org $/ 10.1080 / 10833196.2018 .1450327$

44. Schlipalius M, Delany C. Clinical Reasoning for Inter-professional Pregnancy Care: Everyone On The Same Page! [Presentation] AMEE Conference. Basel, Switzerland. 2018.

45. Dogba MJ, Menear M, Stacey D, Brière N, Légaré $\mathrm{F}$. The Evolution of an Interprofessional Shared Decision-Making Research Program: Reflective Case Study of an Emerging Paradigm. Int J Integr Care. 2016;16(3):4, pp. 1-11. 